www.jmscr.igmpublication.org

Index Copernicus Value: 79.54

ISSN (e)-2347-176x ISSN (p) 2455-0450

crossref DOI: https://dx.doi.org/10.18535/jmscr/v7i4.109

\title{
Management of Clubfoot with Accelerated Ponseti Casting Method at Tertiary Care Hospital, GMC Jammu India
}

\author{
Authors \\ Dr Malik Naseer Ahmad ${ }^{1}$, Dr Abdul Ghani ${ }^{2}$, Dr Sheikh Kalid Nissar ${ }^{3}$ \\ ${ }^{1,3}$ Resident Orthopaedics, GMC Jammu, India \\ ${ }^{2}$ Associate Professor Orthopaedics, GMC Jammu, India
}

\begin{abstract}
Objective: The study was to evaluate the outcome of accelerated ponseti cast technique for clubfoot at the tertiary care hospital, GMC Jammu india.

Methodology: We conducted a prospective randomised controlled trial to study the results of an accelerated ponseti twice-weekly casting method for the treatment of idiopathic congenital talipes equinovarus at tertiary care hospital from June 2016 to October 2018. A total of 40 patients (57 feet) were included in the study. Patient's feet were scored according to modified Pirani scoring system. On each cast removal, improvement in Pirani score was noted. Primary outcome measure was deformity correction.

Results: Total 40 patients with 57 clubfoot include in our study There were 27 males (67.5\%) and 13 (32.5\%) females. Bilateral deformity was present in 17(42.5\%) patients where as $23(57.5 \%)$ patients had unilateral clubfoot. Average Pirani score before casting was 4.69 (3.5-6). Average Pirani score posttreatment was 0.48. The average number of cost applied was 5.14 (4-7). Out of 57 feet, tenotomy was done to 53 feet (92.98\%). The average time required for correction from onset of ponseti cast till correction of equinus is 15.5 days (11-20 days). Out of 57 feet, 52 feet (91.22\%) were treated successfully using the accelerated Ponseti method.

Conclusions: A twice-weekly Ponseti casting protocol enables completion of the casting period earlier than the standard Ponseti method.
\end{abstract}

\section{Introduction}

Congenital talipes equinovarus (CTEV) or clubfoot is one of the most common pediatric foot deformity occurs at 1 in 1000 live births ${ }^{[1,2]}$. It consists of four components: Ankle equines, hindfoot varus, forefoot adductus, and midfoot cavus ${ }^{[3-6]}$. The aim of treatment is to correct the deformities, achieve a functional, plantigrade foot, enabling the patient to wear usual shoes, and to prevent arthritic degenerations in adult hood without surgical correction ${ }^{[7]}$. Because, surgical treatment has multiple complications on the clubfoot, lead to induce some complications such as stiffness of foot, arthritic problems and poor quality of life conservative method has become popular treatment method ${ }^{[8,9]}$. Also ponseti method has been shown to have good inter observer reliability and reproducibility ${ }^{[10,11]}$. The method has been reported to have short-term success rates approaching $90 \%$ and the long-term results have been equally impressive ${ }^{[12]}$. Treatment by Ponseti method involves serial 
casting, percutaneous tenotomy and application of braces. This therapy requires an average of 5 weeks to reach the desired correction for all aspects of the deformity with the exception of the equinus. Modified accelerated treatment protocols were designed: 5-day protocol developed by Morcuende et $\mathrm{al}^{[13]}$. Which included manipulation and casting every 5 days instead of the traditional 7-day protocol and twice weekly protocol by $\mathrm{Xu}^{[14]}$ who did manipulation and casting twice a week; they found that the feet were corrected at a significantly shorter time as compared to the traditional protocol with equivalent outcomes. This modification leads to a reduction of the total length of the treatment. The aim of this study was to evaluate the success in deformity correction by using accelerated ponseti method of twice-weekly regimen in our set up.

\section{Methods}

This study was done at Government Medical College, Jammu. 20 children with 57 clubfoot were studied. Study design was a prospective case series study.

Only idiopathic cases of both genders less than 1 year were included. Syndromic child, relapsed, neglected, resistant and recurrent cases were excluded.

After a, thorough clinical examination and confirmation of diagnosis, Severity was assessed by modified Pirani scoring system. Each parameter was scored according to the Modified Pirani Score (table 1). Six clinical signs are each scored 0 (normal), 0.5 (mildly abnormal) or 1 (severely abnormal). Thus, each foot can receive a Midfoot score between 0-3 and a hindfoot score between 0-3 and a total score between 0-6

\section{Table 1}

\begin{tabular}{|l|c|c|c|}
\hline HIND FOOTSCORE & MILD & MODERATE & SEVERE \\
\hline Posterior crease & 0 & 0.5 & 1 \\
\hline Rigid equinus & 0 & 0.5 & 1 \\
\hline Empty heel & 0 & 0.5 & 1 \\
\hline MID FOOTSCORE & & & \\
\hline Curved lateral border & 0 & 0.5 & 1 \\
\hline Medial foot crease & 0 & 0.5 & 1 \\
\hline Talus head coverage & 0 & 0.5 & 1 \\
\hline
\end{tabular}

application was done with the child comfortably placed in mother's lap. On each cast removal improvement in pirani score was noted. In all patients, the cavus is corrected first by extended the first metatarsal and supinating the forefoot. This elevates the first ray and puts the forefoot in proper alignment with the hindfoot. In second the varus and adduction of mid foot was corrected by abducting the supinated foot with counter pressure applied with the thumb against the head of the talus. Casting was stopped when midfoot and hindfoot scores were zero with 70 degrees of abduction of the forefoot. With abduction of 70 degrees if dorsiflexion was less than 10 degrees then percutaneous tenotomy of the Achilles tendon was performed. All cases were done in operation theatre under local anesthesia as an outpatient procedure. Patients were monitored for 1hour post operatively. A long leg cast was applied in 70 degrees of abduction and maximum available dorsiflexion immediately after tenotomy and maintained for further 3 weeks to allow healing of the tendon. After 3 weeks cast was removed and foot abduction brace was applied.

Number of cast and days of treatment noted were before the last cast for 3 weeks. Children were reviewed every month and Pirani scores were documented. Foot abduction brace was worn for 23 hours during first three months after casting and then at night until child is about 4 years old. Foot-abduction brace is used to maintain the correction. This brace consists of a bar with shoes attached at the ends at 70 degrees of outward rotation on the affected side and 40 degrees on the normal side. The length of the bar should be equal to the width of the child's shoulders. Parent selfreport on brace wear was used to assess compliance. Noncompliance was defined when the foot abduction brace was not used for at least 10 hours a day.

\section{Result}

Total 40 patients with 57 clubfoot include in our study. Mean age at presentation of all patients was 
13.5 weeks. The most common age at presentation was between 0 to 16 weeks (Table no. 2).

Table no. 2

\begin{tabular}{|l|c|c|}
\hline Age in weeks & No of child & Percentage \\
\hline $0-6$ & 14 & $35 \%$ \\
\hline $7-12$ & 7 & $17.5 \%$ \\
\hline $13-18$ & 9 & $22.5 \%$ \\
\hline $19-24$ & 2 & $0.5 \%$ \\
\hline $25-30$ & 3 & $0.75 \%$ \\
\hline $31-36$ & 4 & $1.0 \%$ \\
\hline$>36$ & 1 & $0.25 \%$ \\
\hline
\end{tabular}

There were 27 males (67.5\%) and $13(32.5 \%)$ females (Table no. 3 ).

Table no. 3

\begin{tabular}{|l|c|c|}
\hline Particulars & Number & Percentage \\
\hline Male & 27 & $67.5 \%$ \\
\hline Female & 13 & $32.5 \%$ \\
\hline
\end{tabular}

Bilateral deformity was present in $17(42.5 \%)$ patients where as $23(57.5 \%)$ patients had unilateral clubfoot (Table no. 4).

Table no. 4

\begin{tabular}{|l|c|c|}
\hline Particulars & Number & Percentage \\
\hline Unilateral & 23 & 57.5 \\
\hline Bilateral & 17 & 42.5 \\
\hline
\end{tabular}

Average Pirani score before casting was 4.69 (3.56). Average Pirani score post-treatment was 0.48 . The average number of cost applied was 5.14 (Table no. 5).

\section{Table no. 5}

\begin{tabular}{|l|c|}
\hline Pirani score & No. of patient \\
\hline 3.5 & 6 \\
\hline 4 & 10 \\
\hline 4.5 & 13 \\
\hline 5 & 17 \\
\hline 5.5 & 6 \\
\hline 6 & 5 \\
\hline
\end{tabular}

Out of 57 feet, tenotomy was done to 53 feet (92.98\%) (Table no.6).

\section{Table no. 6}

\begin{tabular}{|l|c|c|}
\hline No. of feet & Tenotomy & Percentage \\
\hline 57 & 53 & $92.98 \%$ \\
\hline
\end{tabular}

The average time required for correction from onset of ponseti cast till correction of equinus is 15.5 days (11-20 days) .The average duration of follow-up was 15 months (12-18 month). Correction was obtained in all cases among the 57 feet. Relapse was seen in only 5 cases. Relapses were treated with a second series of manipulation and casting, followed by the use of the footabduction brace. 52 feet $(91.22 \%)$ were treated successfully using the accelerated Ponseti method.

\section{Discussion}

The ponseti technique is a specific method of manipulation, to stretch contracted ligaments and hold the stretch with serial casting followed by Achilles tendon tenotomy and Bracing-Foot abduction brace ${ }^{[15,16,17]}$. The goal of the treatment is to obtain a foot that is pain free plantigrade mobile and functional with normal appearance. Ponseti believed that a minimum of five days was required between each cast application and advocated a rigid sequence of weekly manipulation and cast application. However our study employed a shorter duration between casts (twice weekly). The study showed that patients who were treated with the accelerated Ponseti protocol of twice weekly casts were able to complete their treatment within a shorter period. accelerated Ponseti protocols was first advocated by $\mathrm{Xu} \mathrm{R.J^{[14] }}$ in his study on a twice weekly accelerated Ponseti treatment, which showed a shorter casting period in patients with the accelerated group compared with those managed with the regular Ponseti treatment.

The largest comprehensive study of an accelerated Ponseti method was undertaken by Morcuende et al. $2005^{[13]}$ who undertook a retrospective, nonrandomized study of 319 feet in 230 patients with clubfoot who were treated over an 11 years period. Their patients were divided into two groups based on their location. One group had an accelerated treatment with five-daily cast changes while the second group had the regular weekly cast changes. Their study showed shorter overall treatment period in the five-day group compared with the standard weekly casts. Sana Ullah, Muhammad Inam, Muhammad Arif et al. found that a total of 28 patients (40 feet) and 2 casts per week was applied. 34(85\%) feet were fully corrected (14) by accelerated Ponseti technique [18]. 
Male to female ratio is our study is $2.1: 1$ ) which is in consistent with in comparison to the series of Cowell and Wein ${ }^{[19]}$ and Yamamoto ${ }^{[20]}$ (male: female $3: 1$ ).This was explained by the Palmer ${ }^{[21]}$ in his study that females require a greater number of predisposing factors than males to produce a clubfoot deformity.

In our study the average number of cost applied to correction was 5.14 (4-7), which correspond to the study by Elgohary and Abulsaad ${ }^{[8]}$, in which the average of $5.16 \pm 0.72$ in the accelerated Ponseti group were applied, In other study by Pulak S. et al. ${ }^{[22]}$ average number of cast applied were 4.9 (3 to 10 casts). Similar results have been seen in Morcuende et al. ${ }^{[13]}$ in which they showed that $90.0 \%$ of the patients required five or fewer casts. Higher Pirani score and older age of patient in our study were associated with an increase in the number of casts required to correct deformity. Harnett et al. ${ }^{[23]}$ compared an accelerated Ponseti protocol of three-weekly casts with the standard Ponseti treatment in Malawi. The study involved 61 feet in 40 patients with 29 feet treated with the thrice weekly protocol and 32 feet treated with the standard weekly protocol. Their study showed no difference in the number of casts required between the accelerated group and the standard group.

In our study the average number of days in cast required for correction from onset of ponseti cast till correction of equinus is 15.5 days (11-20 days), the result was consistent with study by Elgohary HS et al. ${ }^{[24]}$ in which the accelerated group achieved full correction of clubfoot from 11 to 12 days (castings twice per week). In

Morcuende et al. 2005 ${ }^{[13]}$ accelerated Ponseti techniques with every 5 days casting instead of 7 days once, and $\mathrm{Xu}^{[14]}$ studied with casting twice a week, and the results of both studies showed successful correction as same as traditional method and also the duration of the treatment period was less than the original method. Sætersdal C, et al. ${ }^{[25]}$ in there study showed the range of motion as well as Pirani score; the mean Pirani score was 4.8 before the treatment. Thereafter, Pirani score of 0 or 0.5 in $78 \%$ of the patients, 1 or 1.5 in $22 \%$ of the patients, 3.5 score was noted only one patients. In our study the average pirani score was Pirani score at the onset of the cast and after the correction were respectively.

\section{Conclusion}

The study has demonstrated that faster correction of idiopathic clubfoot deformity can be achieved with an accelerated Ponseti protocol of twice weekly casts. The accelerated was safe and reproducible, the accelerated method of cast was convenient to patient and due to the quick result and relatively less time in cast both patient and parents were satisfied . in our study there was no untoward effects in terms of swelling of the feet in the casts.

\section{References}

1. Dobbs MB, Gurnett CA. Update on clubfoot: etiology and treatment. Clinical orthopaedics and related research. 2009; 467(5): 1146.

https://doi.org/10.1007/s11999-009-0734-9

PMID: 19224303

2. Davies RW. Family studies and the cause of congenital club foot, talipes equinovarus, talipes calcaneo- valgus and metatarsus varus. J Bone Joint Surg Br 1964; 46:44563. PMID: 14216453

3. Ponseti IV. Congenital clubfoot: fundamentals of treatment: Oxford University Press, USA; 1996.

4. Simons GW, Sarrafian S. The microsurgical dissection of a stillborn fetal clubfoot. Clinical orthopaedics and related research. 1983; 173:275-83.

5. Mckay DW. New concept of and approach to clubfoot treatment. Journal of Pediatric Orthopaedics. 1982; 2(4):347-56. PMID: 7142383.

6. Irani RN, Sherman MS. The Pathological Anatomy of Club Foot. JBJS. 1963; 45(1):45-52. 
7. Cosma DI, Vasilescu DE. Ponseti treatment for clubfoot in Romania: a 9-year singlecentre experience. Journal of Pediatric Orthopaedics B. 2014;23(6):512-6.

8. Morcuende JA, Dolan LA, Dietz FR, Ponseti IV. Radical reduction in the rate of extensive corrective surgery for clubfoot using the Ponseti method. Pediatrics 2004;113:376-80.

9. Lehman WB, Mohaideen A, Madan S, Scher DM, Van Bosse HJ, Iannacone M, et al. A method for the early evaluation of the Ponseti (Iowa) technique for the treatment of idiopathic clubfoot. J Pediatr Orthop. 2003;12(2):133-40.

10. Siapkara A, Duncan R. Congenital talipes equinovarus: a review of current management. J Bone Joint Surg [Br] 2007;89B:995-1000. 12. Flynn JM, Donohue M,

11. Mackenzie WG. An independent assessment of two club- foot-classification systems. $J$ Pediatr Orthop 1998;18:323-7.

12. Dobbs MB, Rudzki JR, Purcell DB, Walton T, Porter KR, Gurnett CA. Factors predictive of outcome after use of the Ponseti method for the treatment of idiopathic clubfeet. J Bone Joint Surg. 2004;86:22-7.

13. Morcuende JA, Abbasi D, Dolan LA, Ponseti IV. Results of an accelerated Ponseti protocol for clubfoot. J Pediatr Orthop. 2005; 25(5):623-626. Ponseti IV. Treatment of congenital club foot. JBJS. 1992;74(3):448-54.

14. Xu RJ. A modified Ponseti method for the treatment of idiopathic clubfoot: a preliminary report. Journal of Pediatric Orthopaedics. 2011;31(3):317-9. pmid:21415693.

15. Cooper DM, Dietz FR. Treatment of idiopathic clubfoot. A thirty-year follow-up note. J Bone Joint Surg Am. 1995;77(10):1477-89.
16. Laaveg S, Ponseti IV. Long-term results of treatment of congenital club foot. The Journal of Bone \&Joint Surgery. 1980;62(1):23-31.

17. Sana Ullah, Muhammad Inam, Muhammad Arif. Club foot management by accelerated Ponseti technique. http://www.scopemed.org/?mno=170854 15 J Bone Joint Surg Br. 2011; 93(3):404-8.

18. Cowell HR, Wein BK. Genetic aspect of clubfoot. J Bone Joint Surg Am. 1980;62(8):1381-1384.

19. Yamamoto H. A clinical, genetic and epidemiologic study of congenital clubfoot. Jinrui Idengaku Zasshi. 1979;24(1):37-44.

20. Palmer RM. Genetics of talipes equinus varus. J Bone Joint Surg Am. 1964;46:542556.

21. Elgohary HS, Abulsaad M. Traditional and accelerated Ponseti technique: a comparative study. European Journal of Orthopaedic Surgery \& Traumatology. 2015;25(5):949-5

22. Pulak S. Treatment of idiopathic clubfoot by Ponseti technique of manipulation and serial plaster casting and its critical evaluation. Ethiop J Health Sci. 2012, 22.

23. Harnett P, Freeman R, Harrison WJ, Brown LC, Beckles V. An accelerated Ponseti versus the standard Ponseti method. J Bone Joint Surg [Br] 2011;93- B:404-8

24. Elgohary HS, Abulsaad M. Traditional and accelerated Ponseti technique: a comparative study. European Journal of Orthopaedic Surgery \& Traumatology. 2015;25(5):949-53

25. Sætersdal C, Fevang JM, Fosse L, Engesæter LB. Good results with the Ponseti method: a multicenter study of 162 clubfeet followed for 2-5 years. Acta orthopaedica. 2012;83(3):288-93. pmid:22616746. 